\title{
Adverse events in Chinese human immunodeficiency virus (HIV) patients receiving first line antiretroviral therapy
}

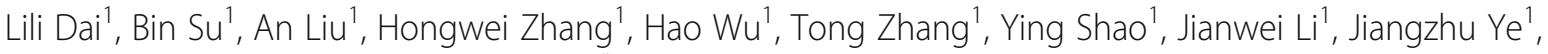
Shaoli Bai ${ }^{2}$, Xiaoling Guo ${ }^{2}$ and Lijun Sun ${ }^{*}$

\begin{abstract}
Background: Although the global human immunodeficiency virus (HIV) epidemic has improved significantly due to antiretroviral treatment (ART), ART-related adverse events (AEs) remain an issue. Therefore, investigating the factors associated with ART-related AEs may provide vital information for monitoring risks.

Methods: A prospective cohort study was conducted among adult patients (aged 18 years or older) with HIV who received Tenofovir (TDF) + Lamivudine (3TC) + Efavirenz (EFV) as first-line ART regimens. All AEs during the first 12 months of therapy were recorded. Logistic regression analysis was used to identify variables associated with AEs.

Results: Four hundred seventy-four patients receiving TDF+ 3TC+ EFV ART regimens between March 2017 and October 2017 were included in the study analysis. Among them, 472 (99.6\%) experienced at least one AE, 436 (92.0\%) patients experienced at least one AE within 1 month of treatment, 33 (7.0\%) between one and 3 months of treatment, and three (0.6\%) patients after 3 months of treatment. The most commonly reported AE was nervous system (95.6\%) related, followed by dyslipidemia (79.3\%), and impaired liver function (48.1\%). Patients with baseline body mass index (BMI) greater than $24 \mathrm{~kg} / \mathrm{m}^{2}$ (adjusted OR 1.77, 95\%Cl 1.03-3.02), pre-existing multiple AEs (adjusted OR 2.72, 95\% Cl 1.59-4.64), and pre-existing severe AEs (adjusted OR 5.58, 95\% Cl 2.65-11.73) were at increased odds of developing a severe AE. Patients with baseline BMI greater than $24 \mathrm{~kg} / \mathrm{m}^{2}$ (adjusted OR 2.72, $95 \%$ Cl 1.25-5.89) were more likely to develop multiple AEs.

Conclusion: The incidence of ART-related adverse events over a 12-month period in China was high. Baseline BMI greater than $24 \mathrm{~kg} / \mathrm{m}^{2}$, pre-existing multiple AEs, and pre-existing severe AEs were shown to be independent risk factors for developing a severe AE.
\end{abstract}

Keywords: Adverse events, China, Antiretroviral therapy, HIV

\section{Background}

According to the World Health Organization (WHO), approximately 37.9 million people were living with human immunodeficiency virus (HIV) by the end of 2018, with 1.7 million people becoming newly infected in 2017, globally [1]. Among them, 23.3 million people were on antiretroviral therapy (ART) treatment by the end of 2018 [1]. With the advent of ART over the last

\footnotetext{
* Correspondence: guoqingliang0524@163.com

${ }^{1}$ Center for Infectious Diseases, Beijing Youan Hospital, Capital Medical University, Beijing 100069, China

Full list of author information is available at the end of the article
}

two decades, HIV has shifted from what was once a death sentence to a treatable, chronic condition. As a result, China launched its National Free Antiretroviral Treatment Program in 2002. Since that time, more than 220,000 people living with HIV have received free ART, markedly reducing the associated morbidity and mortality of patients living with HIV and acquired immune deficiency syndrome (AIDS) [2].

In general practice, two nucleoside reverse transcriptase inhibitors (NRTIs) and an integrase strand transfer inhibitor (INSTI) are recommended as the preferred first-line ART regimens for patients living with HIV [3-5]. Nonnucleoside reverse transcriptase inhibitors (NNRTIs), such 
as Efavirenz (EFV), are no longer recommended as firstline therapy in developed countries due to their associated increasing levels of pre-treatment resistance and adverse events (AEs) [3-5]. However, EFV is still widely used in developing countries [5]. Under the National Free Antiretroviral Treatment Program in China, 604,160 adults were receiving ART by the end of 2017 [6], where a combination of Tenofovir (TDF), Lamivudine (3TC) and EFV are used as the first line antiviral regimen. Though ART contributes to improved survival and quality of life, adverse events associated with antiviral drugs should not be ignored [7]. AEs may lead to the discontinuation of ART, which in turn may cause therapeutic failure, treatment modifications, and consequently contribute to increased HIV virus resistance and poorer health [8]. Therefore, it is critical to find factors associated with the development of ART-associated AEs. Though several studies have assessed such risk factors in Western and African populations, little evidence exit in China. This study aimed to identify factors associated with first line ART regimen $(\mathrm{TDF}+3 \mathrm{TC}+\mathrm{EFV})$-related adverse events in order to better inform national treatment strategies and improve care for people living with HIV.

\section{Methods}

\section{Study design and population}

This was a prospective study from March 2017 to October 2017 in Beijing You'an Hospital, Capital Medical University in Beijing, China. You'an Hospital is one of the largest infectious disease hospitals in China, treating more than 9000 HIV-positive individuals. Individuals with confirmed HIV diagnosis, aged 18 years or older, whom were receiving TDF $+3 \mathrm{TC}+\mathrm{EFV}$ as their firstline ART regimen were included in the study. People living with HIV who experienced severe opportunistic infections requiring hospitalization and pregnant women were excluded.

\section{Patient and public involvement}

All participants provided written, informed consent prior to enrollment in the study authorizing the use of their data generated from the medical information system. The research question and outcome measures were explained to each participant. Patients themselves were not involved in the recruitment and conduct of the study. This study was approved by the Beijing You'an Hospital Ethics Committee (No. LL2019-038-K).

\section{Follow-up}

Each individual was followed at 2 weeks, 1 month, 2 months, 3 months, 6 months, 9 months, and 12 months after initiation of ART treatment. At baseline, each participant received a series of medical examinations including liver and renal function tests, routine blood work, HBV, HCV, and syphilis tests, lipid profile evaluations, HIV viral load measurements, drug resistance assessments, and CD4 cells count. Participants also completed a standard questionnaire administered by trained researchers in order to collect information on demographic and socioeconomic factors. Sleep quality statistics were measured using the Pittsburgh Sleep Quality Index (PSQI) [9]. Anxiety and depression were measured according to the Hospital Anxiety and Depression scale (HAD) [10]. Data related to liver function, renal function, routine blood work, anxiety scale, and depression scale were collected at 2 weeks, 1 month, 2 months, 3 months, 6 months, 9 months, and 12 months after initiation of treatment. Blood lipid levels were also collected at 3 months, 6 months, 9 months, and 12 months after initiation of treatment. CD4 cell count was measured at three and 12 months after initiation of treatment. Participant's viral load was measured at six and 12 months after initiation of treatment, following national guidelines.

\section{Definition and categorization of adverse events}

Adverse events were defined as a response to ART therapies which are noxious and unintended [11]. The diagnosis and classification of AEs were determined by combining laboratory abnormalities with symptoms reported by the participants. These were then compared using the clinical definitions outlined in the Division of Acquired Immuno Deficiency Syndrome (DAIDS) Table for Grading the Severity of Adult and Pediatric Adverse Events (DAIDS 2017) [12]. The severity of AEs was graded as follows: mild (grade 1), moderate (grade 2), severe (grade 3), life-threatening (grade 4), and death (grade 5) [12]. The cut-off values for different AE parameters are presented in Table S1 in the supplementary file.

We assessed sleep quality using the Chinese version of the Pittsburgh Sleep Quality Index (PSQI). The sleep quality scores range from 0 to 21 , with a PSQI $>5$ indicating some level of sleep disturbance, and a PSQI of > 10 indicating severe sleep disturbance $[9,13]$. Anxiety and depression were assessed using the Hospital Anxiety and Depression scale (HADS) [14]. The associated score represents differing severity of anxiety or depression. The scale ranges from 0 to 7 (no anxiety or depression); 8-10 (mild anxiety or depression); 11-14 (moderate anxiety or depression); and 15-21 (severe anxiety or depression) [15].

A participant was classified as having multiple AEs if he or she experienced more than one of the following abnormal symptoms: liver function abnormality [Alanine aminotransferase (ALT), Aspartate aminotransferase (AST), total bilirubin (TBIL)], impaired renal function 
[estimated glomerular filtration rate (eGFR)], dyslipidemia [total cholesterol (TC), triglyceride (TG), low density lipoprotein cholesterol (LDL-c)], erythrism, and neuropsychiatric adverse events (NPAEs), such as headache, insomnia, anxiety, or depression). The severe AEs were defined as grades 3 and 4 of the aforementioned parameters (Table S1).

\section{Statistical analysis}

All statistical analyses were conducted using $\mathrm{R}$ version 3.3.2. (R Core Team, Vienna, Austria), and two-sided $P$ values $<0.05$ were considered statistically significant. Chi square test (for categorical variables) and analysis of variance (ANOVA, for continuous variables) were used to compare the baseline characteristics. Univariable logistic regression model was used to identify variables associated with AEs. Variables with a $P \leq 0.2$ in univariable analysis were further assessed with a multivariable logistic regression model.

\section{Results}

\section{Incidence of drug discontinuation}

In this study, 504 patients were initially included. Of them, 474 patients (94.0\%) completed 12 months of follow-up and were included in the final analysis. A total of $30(6.0 \%)$ patients discontinued treatment, $16(3.2 \%)$ of which were due to drug-related side effects, 5 (1.0\%) were due to EFV resistance, and $9(1.8 \%)$ were due to other causes. Of the 16 patients who discontinued treatment due to any adverse event, 5 discontinued due to NPAEs (1.0\%), one discontinued due to rash $(0.2 \%)$, five discontinued due to abnormal liver function (1.0\%), two discontinued due to abnormal renal function $(0.4 \%)$, and three discontinued due to dyslipidemia (0.6\%). Of those who discontinued, two discontinued between 0 to 2 weeks after ART initiation ( 0.5 month), 12 at one to 2 months after starting treatment, and two at three to 6 months after EFV treatment.

\section{Baseline characteristics}

The baseline demographic characteristics of the participants are presented in Table 1. From March 2017 to October 2017, 474 patients receiving TDF + 3TC + EFV first-line ART regimens were included in the analysis. The mean age of those initiating ART was $34.0 \pm 10.1$ years. 193 (40.7\%) participants were aged between 18 and 29 years. Four hundred sixty-three participants (97.7\%) were male, 311 (65.6\%) had an educational level of high school of higher.

Incidence of adverse events

The frequency and type of adverse events are shown in Table 2. Of the 474 patients, 472 (99.6\%) of them experienced at least one $\mathrm{AE}$, of which 387 (82.0\%) were
Table 1 Demographic Characteristics of Participants

\begin{tabular}{|c|c|}
\hline Variables & Mean \pm SD $/ \mathrm{N}(\%$ \\
\hline \multicolumn{2}{|l|}{ Sex } \\
\hline Female & $11(2.3 \%)$ \\
\hline Male & $463(97.7 \%)$ \\
\hline Age, years & $34.0 \pm 10.1$ \\
\hline $18-29$ & $193(40.7 \%)$ \\
\hline $30-39$ & $168(35.4 \%)$ \\
\hline $40-49$ & $67(14.1 \%)$ \\
\hline$\geq 50$ & $46(9.7 \%)$ \\
\hline \multicolumn{2}{|l|}{ Marital status } \\
\hline Married/common law marriage & $107(22.6 \%)$ \\
\hline Single/divorced/widowed & $367(77.4 \%)$ \\
\hline \multicolumn{2}{|l|}{ Years of Education } \\
\hline$\leq 9$ years & $88(18.6 \%)$ \\
\hline 10-12 years & 75 (15.8\%) \\
\hline$\geq 13$ years & $311(65.6 \%)$ \\
\hline \multicolumn{2}{|l|}{ Route of HIV infection } \\
\hline Homosexual transmission & $427(90.1 \%)$ \\
\hline Heterosexual transmission & $26(5.5 \%)$ \\
\hline Intravenous drug use & $0(0 \%)$ \\
\hline Others & $21(4.4 \%)$ \\
\hline $\mathrm{BMI}, \mathrm{kg} / \mathrm{m}^{2}$ & $22.3 \pm 3.32$ \\
\hline$<18.5$ & $47(9.9 \%)$ \\
\hline $18.5-23.9$ & $304(64.1 \%)$ \\
\hline $24-27.9$ & $94(19.8 \%)$ \\
\hline$\geq 28$ & $29(6.1 \%)$ \\
\hline $\mathrm{CD} 4+$ cells $/ \mathrm{mm}^{3}$ & $340.7 \pm 241.2$ \\
\hline$\leq 199$ & $119(25.1 \%)$ \\
\hline 200-349 & $146(30.8 \%)$ \\
\hline $350-499$ & $124(26.2 \%)$ \\
\hline$\geq 500$ & $85(17.9 \%)$ \\
\hline \multicolumn{2}{|l|}{ Viral load, copies/ml } \\
\hline$<100,000$ & $382(80.6 \%)$ \\
\hline$\geq 100,000$ & $92(19.4 \%)$ \\
\hline \multicolumn{2}{|l|}{ Hepatitis B status } \\
\hline Positive & $31(6.5 \%)$ \\
\hline Negative & $443(93.5 \%)$ \\
\hline \multicolumn{2}{|l|}{ Hepatitis C status } \\
\hline Positive & $5(1.1 \%)$ \\
\hline Negative & 469 (98.9\%) \\
\hline \multicolumn{2}{|l|}{ Tuberculosis } \\
\hline Yes & $4(0.8 \%)$ \\
\hline No & 470 (99.2\%) \\
\hline \multicolumn{2}{|l|}{ Syphilis } \\
\hline Yes & 149 (31.4\%) \\
\hline
\end{tabular}


Table 1 Demographic Characteristics of Participants (Continued)

\begin{tabular}{ll}
\hline Variables & Mean \pm SD /N(\%) \\
\hline No & $325(68.6 \%)$ \\
WHO Clinical Stage & \\
I + II & $433(91.4 \%)$ \\
III + IV & $41(8.6 \%)$ \\
\hline
\end{tabular}

classified as mild or moderate, while 85 (18.0\%) were classified as severe or life-threatening. Four hundred sixty-three patients (97.7\%) experienced at least one $\mathrm{AE}$ within 3 months of initiating treatment, while 342 patients (72.2\%) experienced at least one AE 3 months after starting treatment. The most commonly reported AEs were NPAEs (95.6\%), followed by dyslipidemia (79.3\%), liver function abnormalities (48.1\%), skin lesions (11.6\%), and renal problems (6.5\%). Among severe AEs, the most prominent were increased dyslipidemia (10.1\%), NPAEs (4.6\%), impaired liver function (4.2\%), renal problems $(0.4 \%)$, and skin lesions $(0.2 \%)$.

\section{Predictors of adverse events}

Patients with baseline BMI greater than $24 \mathrm{~kg} / \mathrm{m}^{2}$ (adjusted OR 1.77, 95\% CI 1.03-3.02), pre-existing multiple AEs (adjusted OR 2.72, 95\%CI 1.59-4.64), and preexisting severe AE (adjusted OR 5.58, 95\%CI 2.65-11.73) were at increased odds of developing a severe $\mathrm{AE}$ (Table 3 ). Age, marital status, education, CD4 count, viral load, syphilis status, hepatitis status, WHO clinical stage at baseline, and pre-existing severe AEs were not significantly associated with incident severe AE. Patients with baseline BMI greater than $24 \mathrm{~kg} / \mathrm{m}^{2}$ (adjusted OR 2.72, 95\%CI 1.25-5.89) were at increased odds of developing multiple AE (Table 4). Age, marital status, education, CD4 count, viral load, syphilis status, hepatitis status, and WHO clinical stage, and pre-existing severe AEs were not significantly associated with developing multiple AEs.

\section{Discussion}

This is the first prospective cohort study to assess the incidence, type, severity, and predictors of adverse events in patients who were initiated on TDF + 3TC + EFV ART in China. We found that almost $100 \%$ of patients experienced at least one adverse event, while approximately $20 \%$ experienced at least one severe AE. The most common severe adverse events in this study were NPAEs, dyslipidemia, and liver function abnormalities. Participants whose baseline BMI was greater than $24 \mathrm{~kg} / \mathrm{m}^{2}$, had pre-existing multiple AEs, and pre-existing severe AEs, were shown to be at increased odds for developing a severe AE. Our findings regarding the risk factors for AEs (i.e. BMI greater than $24 \mathrm{~kg} / \mathrm{m}^{2}$, pre-existing multiple AEs, and pre-existing severe AEs) are important, as they suggest that practical interventions to correct these factors could be implemented in clinical practice in order to reduce the risk of an incident $\mathrm{AE}$.

Table 2 Frequency of the most common adverse events

\begin{tabular}{|c|c|c|c|c|c|c|}
\hline \multirow[b]{2}{*}{ Adverse Event } & \multicolumn{3}{|l|}{ Baseline } & \multicolumn{3}{|c|}{ After treatment } \\
\hline & Grade 1-2 & Grade 3-4 & Total & Grade 1-2 & Grade 3-4 & Total \\
\hline Liver function & $97(20.5 \%)$ & $2(0.4 \%)$ & $99(20.9 \%)$ & $208(43.9 \%)$ & $20(4.2 \%)$ & $228(48.1 \%)$ \\
\hline ALT & $31(6.5 \%)$ & $1(0.2 \%)$ & $32(6.8 \%)$ & $181(38.2 \%)$ & $14(3.0 \%)$ & $195(41.1 \%)$ \\
\hline AST & 63(13.3\%) & $0(0 \%)$ & $63(13.3 \%)$ & $144(30.4 \%)$ & $13(2.7 \%)$ & $157(33.1 \%)$ \\
\hline TBIL & $33(7 \%)$ & $1(0.2 \%)$ & $34(7.2 \%)$ & $17(3.6 \%)$ & $3(0.6 \%)$ & $20(4.2 \%)$ \\
\hline \multicolumn{7}{|c|}{ Impaired renal function } \\
\hline eGFR & $6(1.3 \%)$ & $1(0.2 \%)$ & $7(1.5 \%)$ & $29(6.1 \%)$ & $2(0.4 \%)$ & $31(6.5 \%)$ \\
\hline Dyslipidemia & $116(24.4 \%)$ & $7(1.5 \%)$ & $123(25.9 \%)$ & $328(69.2 \%)$ & 48 (10.1\%) & $376(79.3 \%)$ \\
\hline $\mathrm{TC}$ & $31(6.5 \%)$ & $0(0 \%)$ & $31(6.5 \%)$ & $253(53.4 \%)$ & $8(1.7 \%)$ & $261(55.1 \%)$ \\
\hline TG & $92(19.4 \%)$ & $3(0.6 \%)$ & $95(20 \%)$ & $265(55.9 \%)$ & $38(8.0 \%)$ & $303(63.9 \%)$ \\
\hline $\mathrm{LDL}-\mathrm{C}$ & $24(5.1 \%)$ & $4(0.8 \%)$ & $28(5.9 \%)$ & $112(23.6 \%)$ & $13(2.7 \%)$ & $125(26.4 \%)$ \\
\hline \multicolumn{7}{|l|}{ Skin lesions } \\
\hline Erythra & $34(7.2 \%)$ & $1(0.2 \%)$ & $35(7.4 \%)$ & $54(11.4 \%)$ & $1(0.2 \%)$ & $55(11.6 \%)$ \\
\hline Nervous system & $328(69.2 \%)$ & $25(5.3 \%)$ & $353(74.5 \%)$ & 431 (90.9\%) & $22(4.6 \%)$ & 453 (95.6\%) \\
\hline Headache & $44(9.3 \%)$ & $0(0 \%)$ & $44(9.3 \%)$ & $51(10.8 \%)$ & $0(0 \%)$ & $51(10.8 \%)$ \\
\hline Insomnia & $321(67.7 \%)$ & $0(0 \%)$ & $321(67.7 \%)$ & 446 (94.1\%) & $0(0 \%)$ & 446 (94.1\%) \\
\hline Anxiety & $115(24.3 \%)$ & $19(4 \%)$ & 134(28.3\%) & $192(40.5 \%)$ & $14(3.0 \%)$ & 206 (43.5\%) \\
\hline Depression & $92(19.4 \%)$ & $12(2.5 \%)$ & 104(21.9\%) & $176(37.1 \%)$ & 14 (3.0\%) & 190 (40.1\%) \\
\hline Total & $367(77.4 \%)$ & $36(7.6 \%)$ & 403(85.0\%) & 387 (81.7\%) & 85 (17.9\%) & 472 (99.6\%) \\
\hline
\end{tabular}


Table 3 Socio-demographic and clinical factors associated with severe adverse events

\begin{tabular}{|c|c|c|c|c|c|}
\hline \multirow[t]{2}{*}{ Characteristic at baseline } & \multirow[t]{2}{*}{ Case/n } & \multicolumn{2}{|l|}{ Crude model } & \multicolumn{2}{|l|}{ Adjusted model } \\
\hline & & $\mathrm{OR}(95 \% \mathrm{Cl})$ & $P$ & $\mathrm{OR}(95 \% \mathrm{Cl})$ & $P$ \\
\hline \multicolumn{6}{|l|}{ Age, years } \\
\hline$<50$ & $77 / 428$ & 1 & & & \\
\hline$\geq 50$ & $8 / 46$ & $0.96(0.43-2.14)$ & 0.920 & & \\
\hline \multicolumn{6}{|l|}{ Marital status } \\
\hline Single/divorced/widowed & $63 / 367$ & $0.80(0.47-1.38)$ & 0.421 & & \\
\hline Married/common law marriage & $22 / 107$ & 1 & & & \\
\hline \multicolumn{6}{|l|}{ Years of Education } \\
\hline$\leq 9$ & 18/88 & $1.22(0.69-2.19)$ & 0.495 & & \\
\hline$>9$ & $67 / 386$ & 1 & & & \\
\hline \multicolumn{6}{|l|}{$\mathrm{BMI}, \mathrm{kg} / \mathrm{m}^{2}$} \\
\hline$<24$ & $54 / 351$ & 1 & & 1 & \\
\hline$\geq 24$ & $31 / 123$ & $1.85(1.12-3.06)$ & 0.016 & $1.77(1.03-3.02)$ & 0.038 \\
\hline \multicolumn{6}{|l|}{$\mathrm{CD} 4+$, cells $/ \mathrm{mm}^{3}$} \\
\hline$\leq 199$ & $21 / 120$ & 1 & & & \\
\hline $200-349$ & $22 / 145$ & $0.84(0.44-1.62)$ & 0.843 & & \\
\hline $350-499$ & $24 / 124$ & 1.13(0.59-2.16) & 0.656 & & \\
\hline$\geq 500$ & $18 / 85$ & $1.27(0.63-2.56)$ & 0.509 & & \\
\hline \multicolumn{6}{|l|}{ Viral load, cells/ml } \\
\hline$<100,000$ & $64 / 382$ & 1 & & 1 & \\
\hline$\geq 100,000$ & $21 / 92$ & $1.47(0.84-2.56)$ & 0.175 & $1.55(0.86-2.81)$ & 0.148 \\
\hline \multicolumn{6}{|l|}{ Syphilis Status } \\
\hline Yes & $24 / 149$ & $0.83(0.50-1.40)$ & 0.483 & & \\
\hline No & $61 / 325$ & 1 & & & \\
\hline \multicolumn{6}{|l|}{ Hepatitis Status } \\
\hline Positive & $7 / 31$ & $1.37(0.57-3.28)$ & 0.487 & & \\
\hline Negative & $78 / 443$ & 1 & & & \\
\hline \multicolumn{6}{|l|}{ WHO Clinical Stage } \\
\hline $1+\|$ & $75 / 433$ & 1 & & & \\
\hline$I I I+I V$ & $10 / 41$ & $1.54(0.72-3.28)$ & 0.262 & & \\
\hline \multicolumn{6}{|l|}{ Pre-existing AE } \\
\hline Yes & $78 / 403$ & $2.19(0.97-4.97)$ & 0.060 & $0.96(0.39-2.34)$ & 0.924 \\
\hline No & $7 / 71$ & 1 & & 1 & \\
\hline \multicolumn{6}{|l|}{ Pre-existing multiple AE } \\
\hline Yes & $49 / 167$ & $3.13(1.93-5.06)$ & $<0.001$ & $2.72(1.59-4.64)$ & $<0.001$ \\
\hline No & $36 / 307$ & 1 & & 1 & \\
\hline \multicolumn{6}{|l|}{ Pre-existing severe AE } \\
\hline Yes & $18 / 36$ & $5.54(2.74-11.19)$ & $<0.001$ & $5.58(2.65-11.73)$ & $<0.001$ \\
\hline No & $67 / 438$ & 1 & & 1 & \\
\hline
\end{tabular}

In this study, $99.6 \%$ of patients experienced at least one $\mathrm{AE}$, which is higher than what has been reported in Brazil (33.6\%) [16], Aferica (40.3/1000 person-years) [17], and India (32.45\%) [18]. The high incidence of $\mathrm{AE}$ in this study might be due to the prospective nature of the study, which could contribute to the identification of mild AEs that might be unfounded in other analyses. What's more, HIV infection is regarded as a traumatic and stressful experience; patients with HIV infection are more likely to exhibit mental health problems than the 
Table 4 Socio-demographic and clinical factors associated with multiple adverse events

\begin{tabular}{|c|c|c|c|c|c|}
\hline \multirow[t]{2}{*}{ Characteristic at baseline } & \multirow[t]{2}{*}{ Case/n } & \multicolumn{2}{|l|}{ Crude model } & \multicolumn{2}{|l|}{ Adjusted model } \\
\hline & & $\overline{\mathrm{OR}(95 \% \mathrm{Cl})}$ & $P$ & $\mathrm{OR}(95 \% \mathrm{Cl})$ & $P$ \\
\hline \multicolumn{6}{|l|}{ Age, years } \\
\hline$<50$ & $364 / 428$ & 1 & & $2.54(0.76-8.51)$ & 0.130 \\
\hline$\geq 50$ & $43 / 46$ & $2.52(0.76-8.37)$ & 0.131 & 1 & \\
\hline \multicolumn{6}{|l|}{ Marital status } \\
\hline Single/divorced/widowed & $314 / 367$ & $0.89(0.47-1.68)$ & 0.723 & & \\
\hline Married/common law marriage & $93 / 107$ & 1 & & & \\
\hline \multicolumn{6}{|l|}{ Years of Education } \\
\hline$\leq 9$ & $75 / 88$ & $0.94(0.49-1.81)$ & 0.849 & & \\
\hline$>9$ & $332 / 386$ & 1 & & & \\
\hline \multicolumn{6}{|l|}{$\mathrm{BMI}, \mathrm{kg} / \mathrm{m}^{2}$} \\
\hline$<24$ & $292 / 351$ & 1 & & 1 & \\
\hline$\geq 24$ & $115 / 123$ & $2.91(1.35-6.27)$ & 0.007 & $2.72(1.25-5.89)$ & 0.012 \\
\hline \multicolumn{6}{|l|}{$\mathrm{CD} 4+$, cells $/ \mathrm{mm}^{3}$} \\
\hline$\leq 199$ & $102 / 120$ & 1 & & & \\
\hline $200-349$ & $119 / 145$ & $0.81(0.421 .56)$ & 0.524 & & \\
\hline $350-499$ & $110 / 124$ & $1.39(0.66-2.93)$ & 0.392 & & \\
\hline$\geq 500$ & $76 / 85$ & $1.49(0.64-3.50)$ & 0.360 & & \\
\hline \multicolumn{6}{|l|}{ Viral load, cells/ml } \\
\hline$<100,000$ & $327 / 382$ & 1 & & & \\
\hline$\geq 100,000$ & $80 / 92$ & $1.12(0.57-2.19)$ & 0.738 & & \\
\hline \multicolumn{6}{|l|}{ Syphilis Status } \\
\hline Yes & 129/149 & $1.09(0.62-1.92)$ & 0.763 & & \\
\hline No & $278 / 325$ & 1 & & & \\
\hline \multicolumn{6}{|l|}{ Hepatitis Status } \\
\hline Positive & $25 / 31$ & $0.67(0.26-1.69)$ & 0.391 & & \\
\hline Negative & $382 / 443$ & 1 & & & \\
\hline \multicolumn{6}{|l|}{ WHO Clinical Stage } \\
\hline $\mid+\|$ & $374 / 433$ & 1 & & & \\
\hline$I I I+I V$ & $33 / 41$ & $0.65(0.29-1.48)$ & 0.651 & & \\
\hline \multicolumn{6}{|l|}{ Pre-existing $\mathrm{AE}$} \\
\hline Yes & $346 / 403$ & $1.00(0.48-2.06)$ & 0.989 & & \\
\hline No & $61 / 71$ & 1 & & & \\
\hline \multicolumn{6}{|l|}{ Pre-existing multiple AE } \\
\hline Yes & $150 / 167$ & $1.72(0.96-3.08)$ & 0.071 & $1.57(0.86-2.84)$ & 0.139 \\
\hline No & $257 / 307$ & 1 & & 1 & \\
\hline \multicolumn{6}{|l|}{ Pre-existing severe $\mathrm{AE}$} \\
\hline Yes & $33 / 36$ & $1.88(0.56-6.32)$ & 0.306 & & \\
\hline No & $374 / 438$ & 1 & & & \\
\hline
\end{tabular}

general population, especially soon after diagnosis [19-21]. Compared with other countries or regions, a systematic review in China revealed a higher prevalence of depression (greater than 60\%) and anxiety (greater than $40 \%$ ) in patients with HIV infection [22], which may have led to an increase NPAEs. In addition, most patients in the current study experienced at least one pre-existing severe $A E$, which might increase the risk of incident AEs. In addition, previous studies suggested that CYP2B6 516 polymorphisms is a major enzyme in the EFV metabolic pathway. 
However, Chen et.al reported that the allelic frequency of CYP2B6 polymorphisms in Chinese population is 0.16 [23], which is different from other populations [24].

Previous studies have demonstrated that Efavirenzbased regimens can lead to adverse effects impacting the central nervous system [25]. Consistently, nervous system AEs were the most commonly reported $\mathrm{AE}$ in our study. Studies evaluating the safety of EFV/TDF/3TC single-tablet regimens have also reported a neuropsychiatric adverse event profile similar to that found in this study [26, 27]. Other research has found that patients using EFV combined with TDF and Emtricitabine (FTC) had higher occurrences of neuropsychiatric events than those using Dolutegravir (DTG) in combination with Abacavir (ABC) and 3TC [28]. We also reported a much higher frequency of NPAEs (95.5\% of patients) than a previous review [29]. With the exception of dizziness, fewer than $10 \%$ of patients exposed to EFV experienced any other specific type of neuropsychiatric event. This may be because the patients in our study were enrolled soon after their HIV diagnosis, with $70.0 \%$ of the patients initiating ART less than 1 month after diagnosis. This may have resulted in the higher baseline abnormal nervous system rate. However, there were no other increases in grade 3-4 NPAEs after 1 year of treatment.

Previous studies reported that patients experiencing severe AEs were more likely to have a lower BMI $[8,30]$. One such study in Ghana found that patients with $\mathrm{BMI}<16 \mathrm{~kg} / \mathrm{m}^{2}$ had increased risk of neuropsychiatric toxicity (aHR: 1.44; 95\% CI: 1.02-2.03) [31], perhaps due to higher blood concentration of EFV, which is expected in underweight people [32]. However, we found that the risk of AE may increase with increased BMI. This discrepancy might be because the Ghana study focused only on EFV neuropsychiatric toxicity, including insomnia (50\%), headaches (8\%), dizziness (7\%), and abnormal dreams (6\%). In our study, we described all major AEs including liver function abnormalities, impaired renal function, dyslipidemia, erythrism, and neuropsychiatric adverse events. Of these, dyslipidemia and liver function abnormalities were believed to be related with higher BMI. When only considering neuropsychiatric adverse events, there was no relation with BMI (data not shown). Additionally, participants in the Ghana study had much lower BMI than those in our study [median (IQR): 22.0 (20.1-24.1) $\mathrm{kg} / \mathrm{m}^{2}$ for current study vs. $20.0(18.0-22.0)$ $\mathrm{kg} / \mathrm{m}^{2}$ for the Ghana study]. Lastly, we found that patients who had at least one pre-existing severe $\mathrm{AE}$ were at increased odds of experiencing an adverse event, signifying that patients with pre-existing AEs will need tailored care in order to prevent the occurrence of AEs.

The relationship between CD4+ count and AEs is inconsistent. Khalili et al., previously reported that there was no significant association between $\mathrm{CD} 4+$ cell count and developing an adverse event [33], which is consistent with findings from our study. Lartey et al., however, reported that patients with CD4+ cell counts higher than 250 cells/mm3 had a higher chance of developing an $\mathrm{AE}$ [34]. Mendes et al., also reported that higher CD4+ cell counts were associated with lower risk of incident $\mathrm{AE}$ [35]. This difference might be due to the different types of AEs reported and different antiretroviral regimens used between studies.

This study has several important strengths. First, the occurrence of $\mathrm{AE}$ was defined according to active surveillance of laboratory and clinical parameters. Second, the prospective design of the study makes it possible to detect the temporal relationship between risk factors and development of an AE. Lastly, we investigated the predictors for various AEs. Despite these strengths, we should also acknowledge several limitations. First, it is possible that there were unmeasured confounders that could affect these associations. Second, participants in our study were from a single center (the Beijing You'an Hospital), thus our results should be generalized with caution.

\section{Conclusions}

Almost $100 \%$ of patients who were initiated on TDF + 3TC + EFV first-line ART in China experienced adverse events. Baseline BMI greater than $24 \mathrm{~kg} / \mathrm{m}^{2}$ and preexisting severe AEs were independent risk factors for experiencing a severe adverse event. Further studies with larger sample sizes are needed to increase awareness of the frequency and types of $\mathrm{AE}$ associated with the use of antiretrovirals in China.

\section{Supplementary information}

Supplementary information accompanies this paper at https://doi.org/10. 1186/s12879-020-4878-2.

Additional file 1: Table S1. Definition of adverse events

\section{Abbreviations}

3TC: Lamivudine; ABC: Abacavir; AEs: Adverse events; AIDS: Acquired immune deficiency syndrome; ART: Antiretroviral treatment; BMI: Body mass index; DAIDS: Division of Acquired Immunodeficiency Deficiency Syndrome; DTG: Dolutegravir; EFV: Efavirenz; HAD: Hospital anxiety and depression scale; HIV: Human immunodeficiency virus; INSTI: Integrase strand transfer inhibitor; NNRTIs: Non-nucleoside reverse transcriptase inhibitors; NRTIs: Nucleoside reverse transcriptase inhibitors; PSQI: Pittsburgh sleep quality index; TDF: Tenofovir

\section{Acknowledgements}

We would like to thank Sarah Robbins Scott (Chinese Center for Disease Control and Prevention) for her suggestions to the study. We apologize in advance to those researchers whose valuable work was not discussed here due to the limited focus or space of this paper.

\section{Authors' contributions}

LD and LS designed the study and provided critical review of the manuscript. TZ, YS, and JL collected the data. LD, BS, and AL reviewed the literature. $L D, H Z$, and HW analyzed the data and wrote the first draft of the 
manuscript. JY, SB, XG, and LS revised the manuscript. All authors have read and approved the manuscript.

\section{Funding}

This work was supported by the National 13th Five-Year Grand Program on Key Infectious Disease Control (Grant number:2018ZX10721102-003-003 to L.D., 2018ZX10302-102 to L. D.2017ZX10202102-005-003 to B. S., 2017ZX10202101-004-001 to T. Z.) and the National Natural Science Foundation of China (Grant number:81601795 to L. D., 81772165 to B. S.,81571973 to H.W.). The funders had no role in the study design, data collection and analysis, decision to publish, or preparation of the manuscript.

\section{Availability of data and materials}

The datasets used and/or analyzed during the current study are available from the corresponding author upon reasonable request.

\section{Ethics approval and consent to participate}

The study was approved by the Ethics Research Committee of Beijing You'an Hospital (No. LL-2019-038-K). All participants provided written, informed consent before they joined the study.

\section{Consent for publication}

Not applicable.

\section{Competing interests}

The authors declare that they have no conflict of interests.

\section{Author details}

${ }^{1}$ Center for Infectious Diseases, Beiijing Youan Hospital, Capital Medical University, Beijing 100069, China. ²Department of Infectious Disease, Lanzhou Pulmonary Hospital, Lanzhou 730046, China.

\section{Received: 10 September 2019 Accepted: 12 February 2020 Published online: 19 February 2020}

\section{References}

1. World health organization, Key facts on HIV/AIDS. https://www.who.int/en news-room/fact-sheets/detail/hiv-aids. Accesssed on April 24,2019.

2. 2014 China AIDS Response Progress report. National Health and Family Planning Commission of The People's Republic of China June, 2014. http:// www.unaids.org/sites/default/files/documents/CHN narrative_report_2014. pdf. Accessed April 24, 2019.

3. Gunthard HF, Aberg JA, Eron JJ, Hoy JF, Telenti A, Benson CA, Burger DM, Cahn P, Gallant JE, Glesby MJ, et al. Antiretroviral treatment of adult HIV infection: 2014 recommendations of the international antiviral society-USA panel. Jama. 2014;312(4):410-25.

4. World Health Organization - Consolidated Guidelines on the Use of Antiretroviral Drugs for Treating and Preventing HIV Infection. Recommendations for a Public health Approach. Second Edition. Geneva: World Health Organization; 2016.

5. Ghosh AK, Osswald HL, Prato G. Recent Progress in the development of HIV-1 protease inhibitors for the treatment of HIV/AIDS. J Med Chem. 2016; 59(11):5172-208.

6. Zanetti HR, Roever L, Goncalves A, Resende ES. Human immunodeficiency virus infection, antiretroviral therapy, and statin: a clinical update. Curr Atheroscler Rep. 2018;20(2):9.

7. Van Damme L, Corneli A, Ahmed K, Agot K, Lombaard J, Kapiga S, Malahleha M, Owino F, Manongi R, Onyango J, et al. Preexposure prophylaxis for HIV infection among African women. N Engl J Med. 2012; 367(5):411-22.

8. Shet A, Antony J, Arumugam K, Kumar Dodderi S, Rodrigues R, DeCosta A. Influence of adverse drug reactions on treatment success: prospective cohort analysis of HIV-infected individuals initiating first-line antiretroviral therapy in India. PLoS One. 2014;9(3):e91028.

9. Buysse DJ, Reynolds CF 3rd, Monk TH, Berman SR, Kupfer DJ. The Pittsburgh sleep quality index: a new instrument for psychiatric practice and research. Psychiatry Res. 1989;28(2):193-213.

10. Snaith RP. The hospital anxiety and depression scale. Health Qual Life Outcomes. 2003;1:29.

11. World Health Organization International drug monitoring: the role of national centers. Geneva; 1972. WHO Technical Report Series 498.
12. National Institutes of Health Division of AIDS (DAIDS) Table for Grading the Severity of Adult and Pediatric Adverse Events, July 2017. Available:https:// rsc.niaid.nih.gov/sites/default/files/daidsgradingcorrectedv21.pdf. Accessed 16 April 2019.

13. Macey PM, Woo MA, Kumar R, Cross RL, Harper RM. Relationship between obstructive sleep apnea severity and sleep, depression and anxiety symptoms in newly-diagnosed patients. PLoS One. 2010;5(4):e10211.

14. Zigmond AS, Snaith RP. The hospital anxiety and depression scale. Acta Psychiatr Scand. 1983;67(6):361-70.

15. Christodoulou C, Michopoulos J, Tournikioti K, Douzenis A, Bouras G, Seretis D, Kontaxakis V, Lykouras L. Hospital anxiety and depression scale. A quantitative analysis in medical outpatients, psychiatric outpatients and normal subjects. Psychiatriki. 2010;21(4):279-86.

16. de Almeida TB, de Azevedo M, Pinto J, Ferry FRA, da Silva GAR, de Castro IJ, Baker P, Tanuri A, Haas DW, Cardoso CC. Drug metabolism and transport gene polymorphisms and efavirenz adverse effects in Brazilian HIV-positive individuals. J Antimicrob Chemother. 2018;73(9): 2460-7.

17. Abah 1O, Akanbi M, Abah ME, Finangwai Al, Dady CW, Falang KD, Ebonyi AO, Okopi JA, Agbaji OO, Sagay AS, et al. Incidence and predictors of adverse drug events in an African cohort of HIV-infected adults treated with efavirenz. Germs. 2015;5(3):83-91.

18. Mukherjee S, Era N, Saha B, Tripathi SK. Adverse drug reaction monitoring in patients on antiretroviral therapy in a tertiary care hospital in eastern India. Indian J Pharmacol. 2017;49(3):223-8

19. Brandt R. The mental health of people living with HIV/AIDS in Africa: a systematic review. Afr J AIDS Res. 2009;8(2):123-33.

20. Clucas C, Sibley E, Harding R, Liu L, Catalan J, Sherr L. A systematic review of interventions for anxiety in people with HIV. Psychol Health Med. 2011;16(5): 528-47.

21. Sherr L, Clucas C, Harding R, Sibley E, Catalan J. HIV and depression-a systematic review of interventions. Psychol Health Med. 2011;16(5): 493-527.

22. Niu L, Luo D, Liu Y, Silenzio VM, Xiao S. The mental health of people living with HIV in China, 1998-2014: a systematic review. PLoS One. 2016;11(4): e0153489.

23. Chen J, Sun J, Ma Q, Yao Y, Wang Z, Zhang L, Li L, Sun F, Lu H. CYP2B6 polymorphism and nonnucleoside reverse transcriptase inhibitor plasma concentrations in Chinese HIV-infected patients. Ther Drug Monit. 2010; 32(5):573-8

24. Cheng L, Wang Y, Li X, Feng W, Weng B, Yuan Q, Xia P, Sun F. Metaanalysis of the associations of CYP2B6-516G>T polymorphisms with efavirenz-induced central nervous system side effects and virological outcome in HIV-infected adults. Pharmacogenomics J. 2019.

25. Fabbiani M, Zaccarelli M, Grima P, Prosperi M, Fanti I, Colafigli M, D'Avino A, Mondi A, Borghetti A, Fantoni M, et al. Single tablet regimens are associated with reduced Efavirenz withdrawal in antiretroviral therapy naive or switching for simplification HIV-infected patients. BMC Infect Dis. 2014;14:26.

26. Rakhmanina NY, van den Anker JN. Efavirenz in the therapy of HIV infection. Expert Opin Drug Metab Toxicol. 2010;6(1):95-103.

27. Avihingsanon A, Maek ANW, Gatechompol S, Sapsirisavat $V$ Thiansanguankul W, Sophonphan J, Thammajaruk N, Ubolyam S, Burger DM Ruxrungtham K. Efficacy and safety of a once-daily single-tablet regimen of tenofovir, lamivudine, and efavirenz assessed at 144 weeks among antiretroviral-naive and experienced HIV-1-infected Thai adults. Int J Infect Dis. 2017;61:89-96.

28. Walmsley SL, Antela A, Clumeck N, Duiculescu D, Eberhard A, Gutierrez F, Hocqueloux L, Maggiolo F, Sandkovsky U, Granier C, et al. Dolutegravir plus abacavir-lamivudine for the treatment of HIV-1 infection. N Engl J Med. 2013;369(19):1807-18

29. Ford N, Shubber Z, Pozniak A, Vitoria M, Doherty M, Kirby C, Calmy A Comparative safety and neuropsychiatric adverse events associated with Efavirenz use in first-line antiretroviral therapy: a systematic review and meta-analysis of randomized trials. J Acquir Immune Defic Syndr. 2015;69(4):422-9.

30. d'Arminio Monforte A, Lepri AC, Rezza G, Pezzotti P, Antinori A Phillips AN, Angarano G, Colangeli V, De Luca A, Ippolito G, et al. Insights into the reasons for discontinuation of the first highly active antiretroviral therapy (HAART) regimen in a cohort of antiretroviral naive patients. I.CO.N.A. Study Group. Italian Cohort of AntiretroviralNaive Patients. AIDS (London, England). 2000;14(5):499-507. 
31. Sarfo FS, Sarfo MA, Chadwick D. Incidence and risk factors for neuropsychiatric events among Ghanaian HIV patients on long-term non-nucleoside reverse transcriptase inhibitor-based therapy. eNeurologicalSci. 2016;3:21-5.

32. Huang SH, Lin SW, Chang SY, Lin YT, Chiang C, Hsiao CF, Sun HY, Liu WC, Su YC, Hung CC, et al. Prediction of plasma efavirenz concentrations among HIV-positive patients taking efavirenz-containing combination antiretroviral therapy. Sci Rep. 2017;7(1):16187.

33. Khalili H, Dashti-Khavidaki S, Mohraz M, Etghani A, Almasi F. Antiretroviral induced adverse drug reactions in Iranian human immunodeficiency virus positive patients. Pharmacoepidemiol Drug Saf. 2009;18(9):848-57.

34. Lartey M, Asante-Quashie A, Essel A, Kenu E, Ganu V, Neequaye A. Adverse drug reactions to antiretroviral therapy during the early art period at a tertiary hospital in Ghana. Pan Afr Med J. 2014;18:25.

35. Mendes JC, Bonolo PF, Ceccato M, Costa JO, Reis AMM, Dos Santos H, Silveira MR. Adverse reactions associated with first-line regimens in patient initiating antiretroviral therapy. Eur J Clin Pharmacol. 2018;74(8):1077-88.

\section{Publisher's Note}

Springer Nature remains neutral with regard to jurisdictional claims in published maps and institutional affiliations.

Ready to submit your research? Choose BMC and benefit from:

- fast, convenient online submission

- thorough peer review by experienced researchers in your field

- rapid publication on acceptance

- support for research data, including large and complex data types

- gold Open Access which fosters wider collaboration and increased citations

- maximum visibility for your research: over $100 \mathrm{M}$ website views per year

At BMC, research is always in progress.

Learn more biomedcentral.com/submissions 